University of Nebraska - Lincoln

DigitalCommons@University of Nebraska - Lincoln

Sociology Department, Faculty Publications

Sociology, Department of

6-2001

\title{
Family Relationship Histories, Intergenerational Relationship Quality, and Depressive Affect among Rural Elderly People
}

Les B. Whitbeck

University of Nebraska-Lincoln, Iwhitbeck2@unl.edu

Dan R. Hoyt

University of Nebraska-Lincoln, dhoyt2@unl.edu

Kimberly A. Tyler

University of Nebraska-Lincoln, kim@ktresearch.net

Follow this and additional works at: https://digitalcommons.unl.edu/sociologyfacpub

Part of the Sociology Commons

Whitbeck, Les B.; Hoyt, Dan R.; and Tyler, Kimberly A., "Family Relationship Histories, Intergenerational Relationship Quality, and Depressive Affect among Rural Elderly People" (2001). Sociology Department, Faculty Publications. 55.

https://digitalcommons.unl.edu/sociologyfacpub/55

This Article is brought to you for free and open access by the Sociology, Department of at DigitalCommons@University of Nebraska - Lincoln. It has been accepted for inclusion in Sociology Department, Faculty Publications by an authorized administrator of DigitalCommons@University of Nebraska - Lincoln. 
Published in The Journal of Applied Gerontology, 20:2 (June 2001), pp. 214-229. Copyright (C) 2001 The Southern Gerontological Society; published by Sage Publications. Used by permission. http://jag.sagepub.com

During the past several years, support for this research has come from multiple sources, including the National Institute of Mental Health (MH00567, MH19734, MH43270, MH48165, and MH51361); the National Institute on Drug Abuse (DA05347); the Bureau of Maternal and Child Health (MCJ109572); the MacArthur Foundation Research Network on Successful Adolescent Development Among Youth in High-Risk Settings; and the Iowa Agriculture and Home Economics Experiment Station (Project No. 3320).

Accepted July 1, 1999.

\title{
Family Relationship Histories, Intergenerational Relationship Quality, and Depressive Affect among Rural Elderly People
}

\author{
Les B. Whitbeck \\ Dan R. Hoyt \\ Iowa State University \\ Kimberly A. Tyler \\ University of Central Florida
}

\begin{abstract}
Based on a sample of matched adult children and aging parents in the rural Midwest, this study examined the effects of family relationship history on depressive symptoms among elderly parents. The study used reports from both adult children and aging parents regarding intergenerational affectional solidarity and relationship strain. Aging parents reported levels of depressed affect. Adult children's recalled early relationships with their parents were associated with elderly parents' reports of depressed affect through the effects of early family relationships on contemporary relationships. Reports of early relationships and contemporary relationships were separated by 5 years. It is suggested that family relationship characteristics persist across time and that family relationship patterns affect the abilities of family members to negotiate support for elderly parents.
\end{abstract}

Although the literature on intergenerational relationships is replete with articles on support and caregiving, surprisingly little attention has been given to the effects of family relationship histories on later life relationship quality between generations. This is remarkable in that family theorists and therapists have long argued that family interaction patterns 
are relatively stable and are potent influences on behaviors and emotional well-being (Jackson, 1965a, 1965b; Rausch, Greif, \& Nugent, 1979) and that they have lifelong consequences for personality development (Caspi, Bem, \& Elder, 1989). Too often, researchers examining intergenerational relations do not acknowledge that families have developmental histories that span the life courses of family members. These developmental histories affect the abilities of family members to recognize and negotiate effective responses to situations that call for family support across the life course (Whitbeck, Hoyt, \& Huck, 1994; Whitbeck, Simons, \& Conger, 1991). The purpose of this article is to examine the effects of family relationship histories on elderly parents' perceptions of positive affect and relationship strain between themselves and their adult children and the effects of these perceptions on the elderly parents' depressive symptoms.

According to a life course developmental perspective, the blueprint for mutual family supportiveness is created through early and persistent family interaction patterns. Interaction styles learned in the family become self-reinforcing and result in the selection and creation of environments that are familiar and congruent with these interaction styles. Caspi et al. (1989) believed that these processes operate over time, "amplifying and elaborating the diverging trajectories of individual's lives to produce enduring individual differences throughout the life course" ( $p$. 377). Such processes result in persistent behavioral patterns that are continually reinforced in interactions with others, a process that Caspi et al. termed "cumulative continuity" (p. 377).

Cumulative continuity of interaction patterns, or "interactional continuity," is particularly salient for family relationships across time. Patterson's (1982) work with aggressive families has shown that coercive interactions within families create self-perpetuating cycles that result in learned patterns of interaction. These interaction patterns are then generalized to other environments, initiating coercive interchanges in response. This interactional continuity is "likely to be observed in the life course whenever the conditions that originally gave rise to the components of the ensemble are replicated" (Caspi et al., 1989, p. 379). The environment most likely to continually replicate interaction patterns is the environment in which people initially develop: the family.

\section{Hypothesized Model}

From this point of view, early family relationships may be expected to have long-term consequences for family supportiveness and hence the well-being of elderly people. We proposed a model (Figure 1) to investigate the effects of early parent-child relationships on the reports of adult children and their parents regarding contemporary adult child-parent re- 
lationships and the well-being of elderly parents. The model begins with the hypothesis that early parental rejection as recalled by adult children will affect their reports of contemporary adult child-parent affection and relationship strain (Arrows A). Adult children's perceptions of contemporary relationship quality (affection and relationship strain) in turn were predicted to influence the amount of contact and emotional support provided to aging parents by their adult offspring (Arrows B). Adult children's reports of relationship quality (affection and relationship strain, Arrows C), contact, and emotional support (Arrows D) were expected to affect elderly parents' reports of affection and relationship strain from their adult children. Finally, elderly parents' perceptions regarding relationship quality were expected to influence their reports of depressive symptoms (Arrows E).

In summary, the hypothesized model investigates the effects of interactional continuity on the ability of family systems to successfully provide support for the emotional well-being of elderly parents. Reports of early family relationship are separated from those of contemporary intergenerational relationship quality by 5 years to reduce retroactive bias from contemporary relationship strain. Also, the model is based on reporters from both generations to better assess the effects of early recalled parent-child relationships on contemporary relationship quality.

\section{Method}

Sample

The analysis was based on matched reports of the parent and grandparent generations from the Iowa Youth and Families Project, an ongoing longitudinal study of Midwestern, rural families. The total sample is made up of 603 adult children (264 men and 339 women) and their elderly parents, resulting in matched pairs of 99 adult sons and fathers, 165 adult sons and mothers, 136 adult daughters and fathers, and 203 adult daughters and mothers.

\section{Adult Children}

Data for adult children (Generation 2 [G2]) for the present study were collected as part of a broader longitudinal study concerned with the impact of changes in the rural economy on family dynamics and adolescent development. A sample of 451 two-parent families was recruited through the cohort of all seventh grade students in eight counties in north central Iowa who were enrolled in public or private schools during the fall 


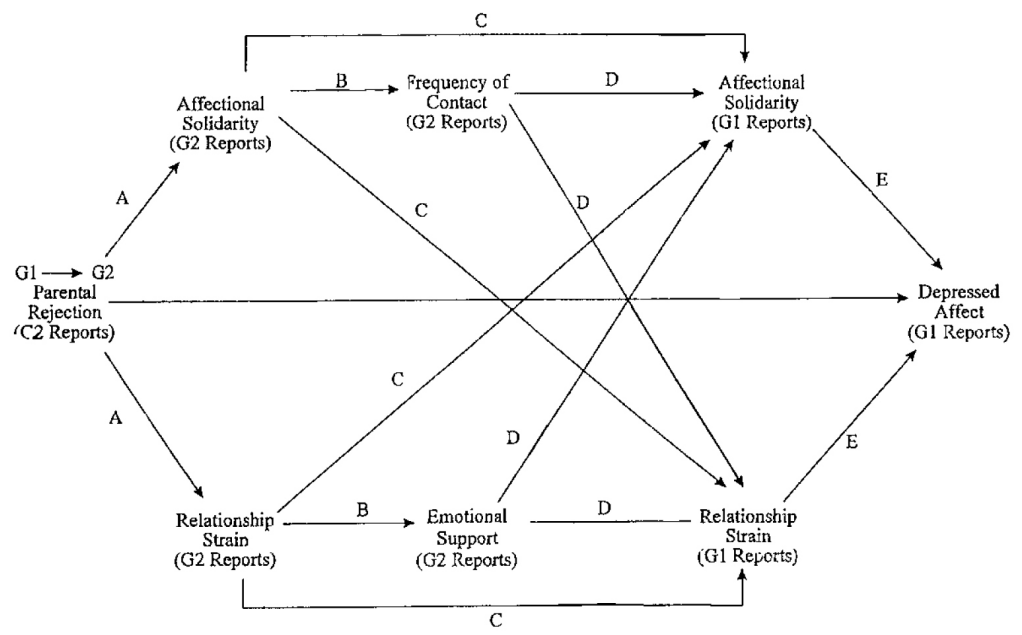

Figure 1. Hypothesized model. G1 = Generation 1, G2 = Generation 2.

term of 1989. Additional criteria for inclusion in the study were a sibling within 4 years of age of the seventh grader and the presence of both biological parents in the home. Seventy-seven percent of the eligible families agreed to participate in the study. Because substantial remuneration appears to be a requisite for obtaining the cooperation of multiple family members (Capaldi \& Patterson, 1987), families in the present project received \$250 for their participation, an amount that translated into about $\$ 10$ per hour for each family member's time.

The families in the study lived in small, agriculturally supported communities or on farms (about one third). All of the families were White. Annual family incomes ranged from $\$ 0$ to $\$ 135,000$ with an average family income of $\$ 29,642$. Fathers' educations ranged from 8 to 20 years in length with a mean of 13.5 years; mothers' educations ranged from 8 to 18 years in length with a mean of 13.4 years. Fathers ranged in age from 31 to 68 years with a median age of 39.7 years. Mothers ranged in age from 29 to 53 years with a median age of 37.7. Because families of fewer than 4 members were excluded from the sampling frame, the families were larger than would be expected in the general population. Families ranged in size from 4 to 13 members with an average size of 4.9 members.

\section{Parents of the Adult Children}

Respondents from the grandparent generation (Generation 1 [G1]) ranged in age from 51 to 91 years with median ages of 70.5 years for fa- 
thers and 69 years for mothers. Nineteen percent of the aging G1 parents lived alone. These intergenerational, rural families tended to live quite close to one another. Sixty-one percent of the G1 parents lived within 25 miles of their adult children. According to adult children's reports, about two thirds $(63 \%)$ reported contact with their aging parents once a week or more. Two thirds of the adult children rated their parents' health as poor or very poor.

\section{Measures}

Parental rejection was measured by adult children's Wave 1 (1989) reports regarding their relationships with each parent when they were "about the same age as their 7th grader." Four items were used to construct an overall measure of parental rejection, including trust, fault finding, caring, and blaming. The response categories ranged from 1 (strongly agree) to 5 (strongly disagree). Items were coded so that a high score indicated a high level of rejection. Cronbach's alpha for this measure was .80 .

G2 reports of affectional solidarity between generations were assessed using a three-item measure at Wave 6 (1994), the first year for which matching data from G1 were available. These items included the degree to which adult children felt loved, appreciated, and cared for by their parents; whether adult children could depend on their parents to be there when needed; and the amount of concern or understanding that the parents showed for their adult children's feelings and problems. The response categories for each indicator ranged from 1 (not at all) to 4 (a lot). A high score on each of the items indicated a high degree of affectional solidarity. The alpha reliability for this measure was .82 .

Contemporary relationship strain was also assessed at Wave 6 using a two-item measure. The first question concerned how much conflict, tension, or disagreement adult children felt between themselves and their parents; the second concerned how critical their parents were of them. Responses ranged from 1 (not at all) to 4 (a lot). A high score indicated a high level of relationship strain. Cronbach's alpha for this measure was .73.

Grandparent affectional solidarity was derived from reports given by members of G1 regarding the amount of affection that they currently received from their adult children. The scale for this item was measured in the same way as for the adult children. The alpha coefficient for this measure was .68.

Grandparent relationship strain was obtained from contemporary reports given by the parents about the amount of strain that they had with their adult children. The measure of strain was assessed in the same way as for the adult children. Cronbach's alpha was .81. 
Depressive symptoms were assessed using 17 items from the Symptom Check List 90 Rating (Derogatis, 1983). Grandparents were asked questions such as whether they were feeling lonely, blue, or hopeless about the future, and whether feeling everything was an effort. The response categories ranged from 1 (not at all) to 5 (extremely). All items were summed so that the higher the score, the higher the depression. Cronbach's alpha for the measure was .88 .

Emotional support was assessed at Wave 6 with a single-item indicator concerning whether the adult children provided emotional support for either parent. Frequency of contact was measured at Wave 6 by asking the adult children how often they had contact with their parents during the past 6 months, either in person, by phone, or by mail. Responses ranged from 1 (every day) to 6 (no contact at all).

The controls for this model included the following variables. Health of the parent was measured by a single item with which the adult children at Wave 6 were asked to assess the overall health of each parent; responses ranged from 1 (excellent) to 5 (very poor). The item was reverse coded so that a high score indicated better health. Geographic proximity was assessed by asking the adult children at Wave 6 how far they lived from each parent. The response categories ranged from 1 (we live together) to 7 (more than 250 miles away). The ages of the G1 parents were measured by asking the adult children the ages of each of their parents. The living situations of the G1 parents were dichotomized so that $0=$ living alone and 1 = living with someone.

\section{Results}

At the bivariate level (Table 1), adult children's and parents' ratings of affectional solidarity were more strongly correlated for mothers $(r=$ .43) than fathers $(r=.24)$. However, reports of relationship strain across generations did not differ by gender of the G1 parent $(r=.29)$. Adult children's reports of early parental rejection were positively correlated with their ratings of contemporary relationship strain $(r=.30$ for G1 mothers, $r=.29$ for G1 fathers) and negatively correlated with their ratings of affectional solidarity ( $r=-.45$ for G1 mothers, $r=-.37$ for G1 fathers). It is noteworthy that these reports were separated in time by 5 years. Early parental rejection was positively correlated with G1 parent reports of depressive symptoms ( $r=.14$ for G1 mothers, $r=.15$ for G1 fathers); negatively correlated with their reports of affectional solidarity ( $r=-.29$ for G1 mothers, $r=-.13$ for G1 fathers); and positively associated with their reports of relationship strain $(r=.26$ for G1 mothers, $r=$ .17 for G1 fathers). 


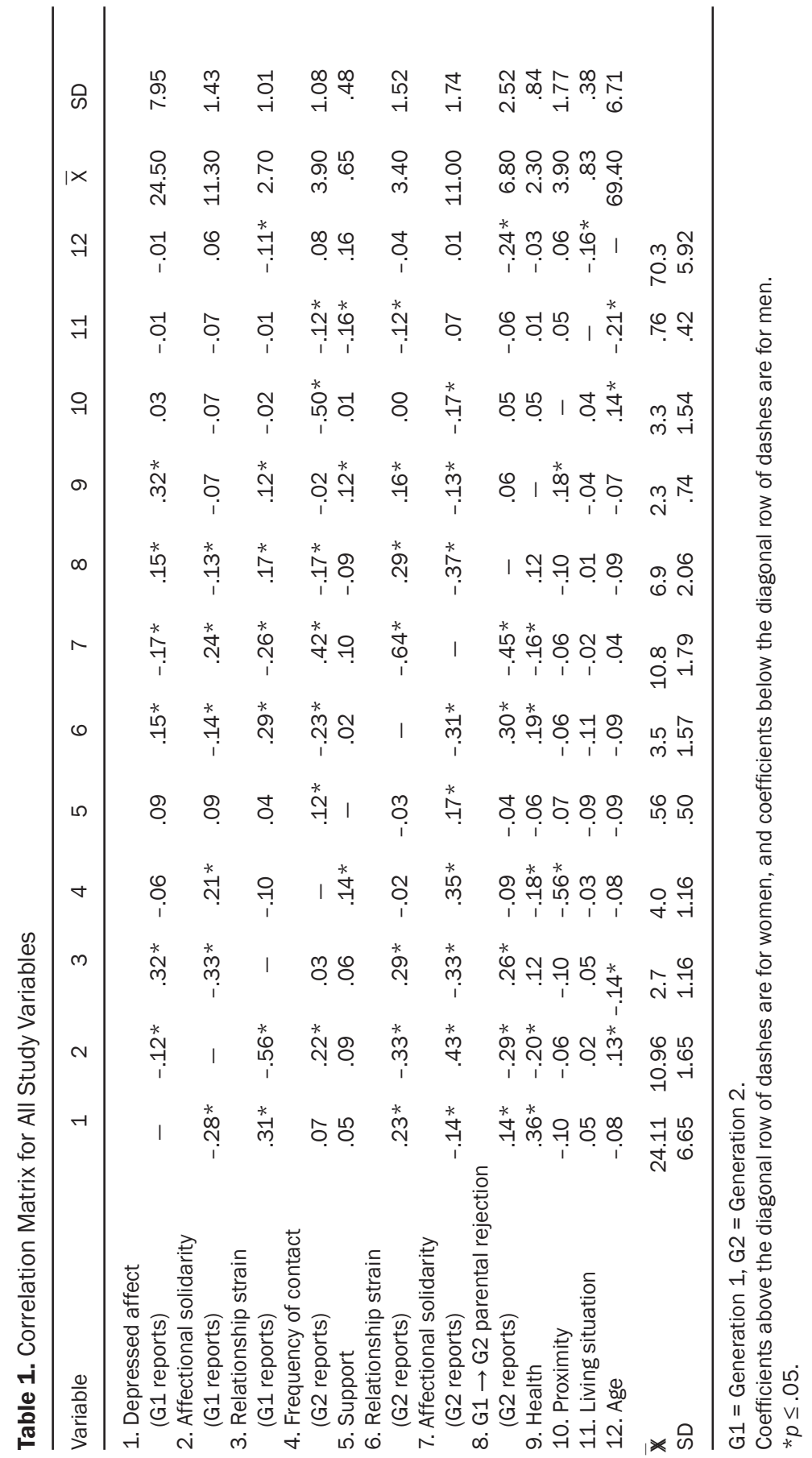


Two path models were run: one for adult children (G2) and mothers (G1) and one for adult children and fathers (G1). Because of the complexity of the models and small cell sizes (e.g., matched adult sons and fathers $=99$ ), separate analyses were not run by gender of grandparent and adult child; instead, gender of adult child was added as a control variable in each of the models.

\section{Model for Adult Children and Their Mothers}

Results for the fully recursive regression models for mothers, including control variables, are presented in Table 2. Results for statistically significant paths for the theoretically important variables are presented in Figure 2.

Although the reports were separated by a period of 5 years, recalled early parental rejection strongly influenced adult children's assessments of their current relationships with their mothers (Figure 2). Early parental rejection was negatively associated with adult children's reports of affectional solidarity with their mothers $(\beta=-.43)$ and positively associated with relationship strain $(\beta=.32)$. Although adult children's reports of early rejection were not related to mothers' reports of contemporary affectional solidarity, they were positively associated with grandmothers' reports of contemporary relationship strain $(\beta=.14)$, suggesting that these reports are indicative of persistent relationship difficulties between generations.

Adult children's reports of affectional solidarity were positively related to frequency of contact $(\beta=.33)$, emotional support $(\beta=.16)$, and mothers' reports of affectional solidarity $(\beta=.19)$. They were negatively related to mothers' reports of relationship strain $(\beta=-.15)$. Adult children's reports of relationship strain were only related to mothers' reports on the same measure $(\beta=.16)$. Emotional support (reported by adult children) was positively associated with mothers' reports of relationship strain $(\beta=.16)$. Mothers' reports of relationship strain in turn were positively associated with their reports of depressive symptoms $(\beta=.32)$. When aging mothers perceived that they were having relationship difficulties with adult sons or daughters, they were more likely to report depressive symptoms. Their reports of affectional solidarity, on the other hand, had no effect on depressive symptoms.

Among the control variables, only health of parent was significantly associated with depressive symptoms $(\beta=.31$, see Table 2$)$. Health of parent was also negatively associated with affectional solidarity in Model $1(\beta=-.10)$ and positively associated with relationship strain in Model 2 $(\beta=.11)$. As one would expect, proximity was strongly associated with frequency of contact $(\beta=-.50)$. Age of parent was associated with mothers' reports of affectional solidarity $(\beta=.12)$. Living alone was associated 


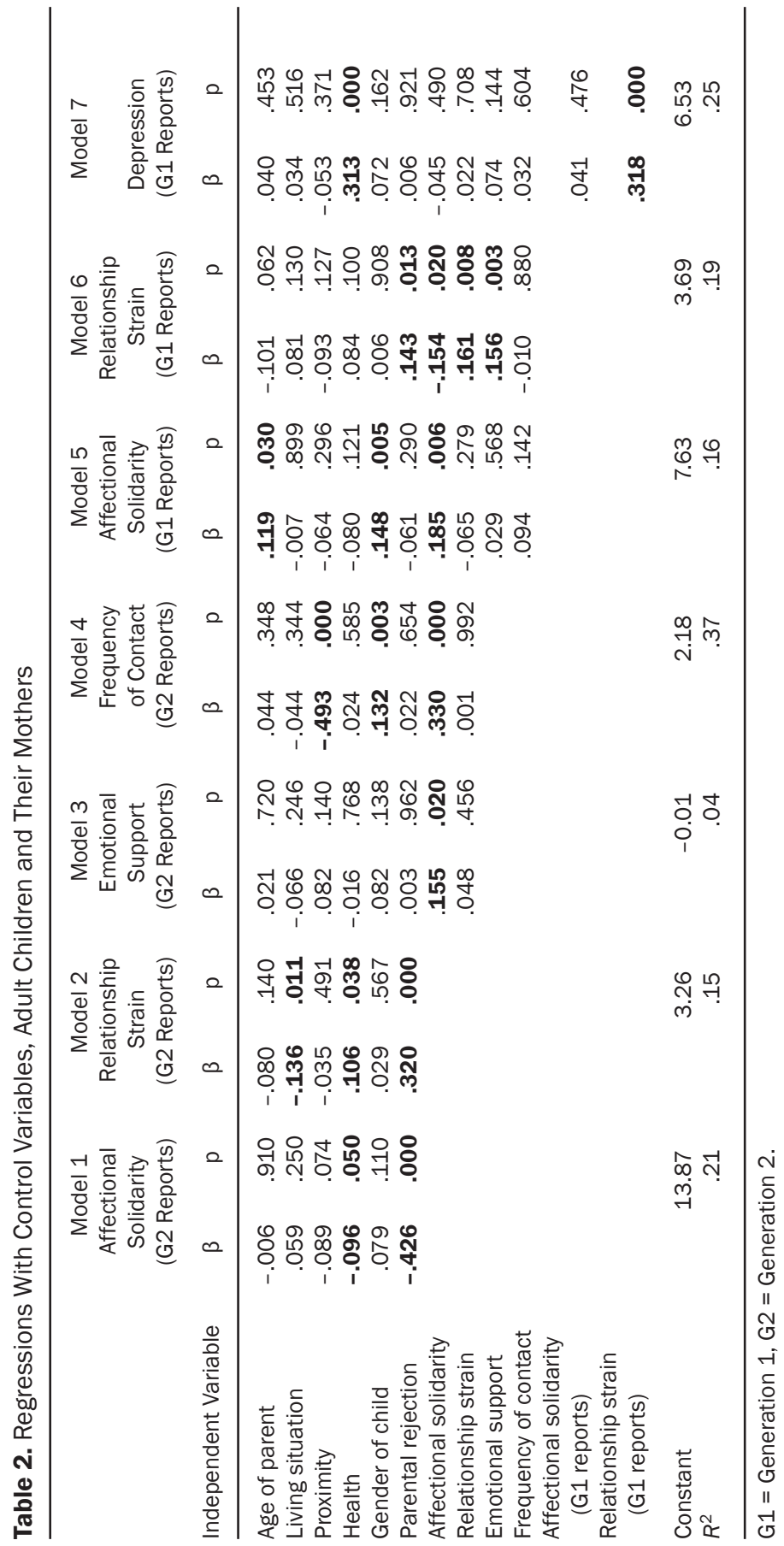



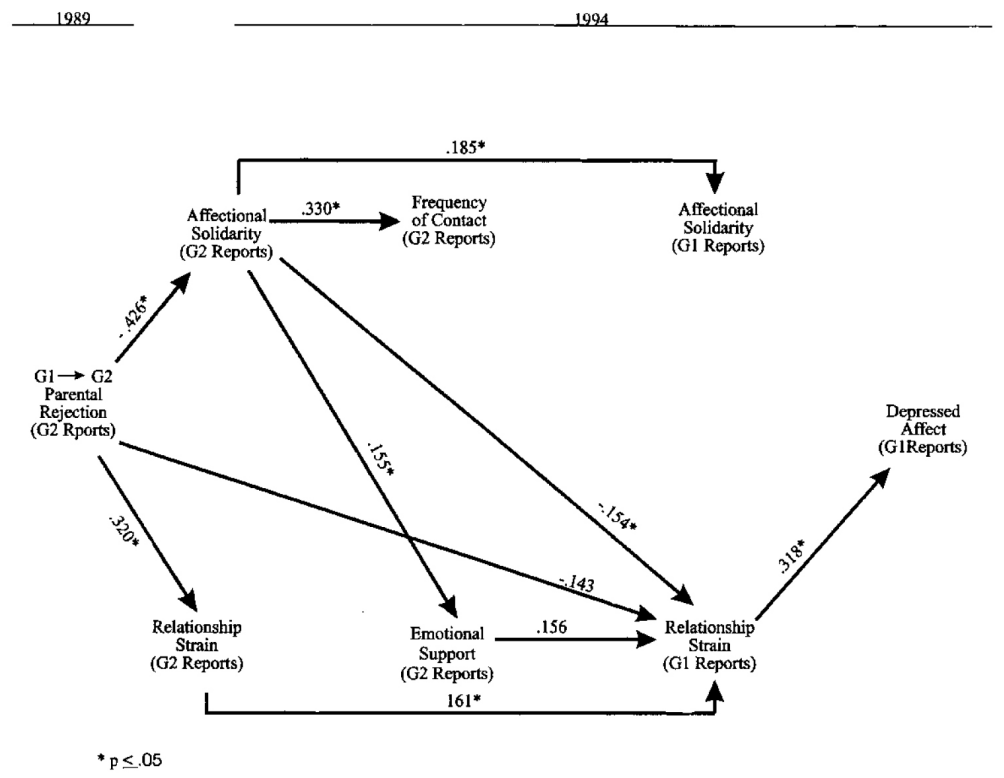

Figure 2. Model for male and female (G2) reports of mothers (G1), showing only statistically significant paths. G1 = Generation $1, \mathrm{G} 2=$ Generation 2. $* p \leq .05$.

with G2 reports of relationship strain $(\beta=-.14)$. Gender of adult child was associated with frequency of contact $(\beta=.13)$ and G1 mother reports of affectional solidarity $(\beta=.15)$. Daughters were more like to see their mothers regularly, and mothers indicated higher levels of affection for daughters than for sons.

The model explained $25 \%$ of the variance of depressive symptoms for aging mothers, $16 \%$ of the variance of mothers' reports of affectional solidarity with adult children, and 19\% of the variance of their reports of relationship strain across generations.

\section{Model for Adult Children and Their Fathers}

Results for the fully recursive regression models for fathers, including control variables, are presented in Table 3. Results for statistically significant, theoretically important variables are illustrated in Figure 3.

The effects of perceived early parental rejection were essentially the same for adult children's reports of their relationships with their fathers as for their mothers $(\beta=-.33$ for affectional solidarity, $\beta=.19$ for relationship strain). Similarly, as in the mothers model, adult children's reports of affectional solidarity with their fathers were positively related 


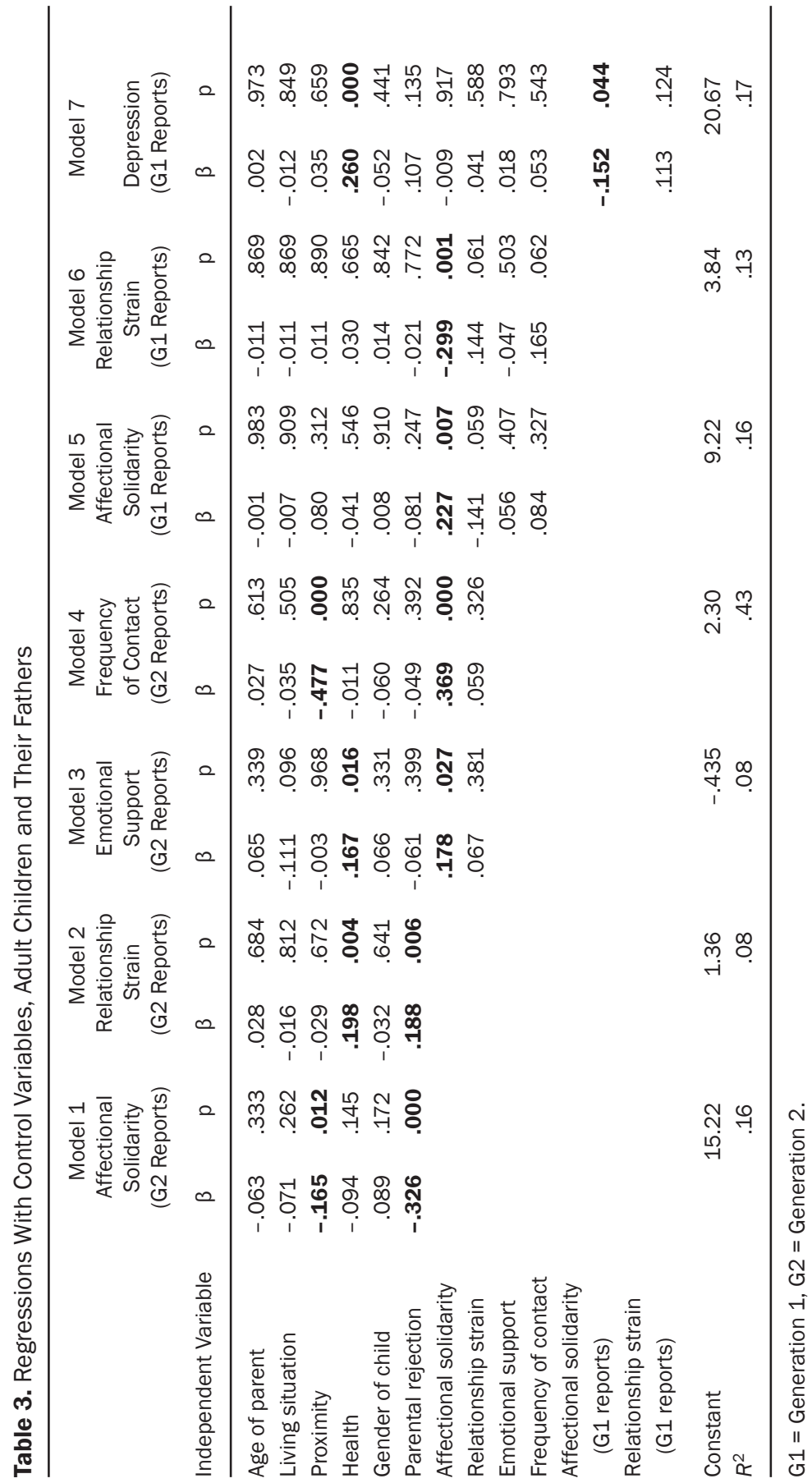



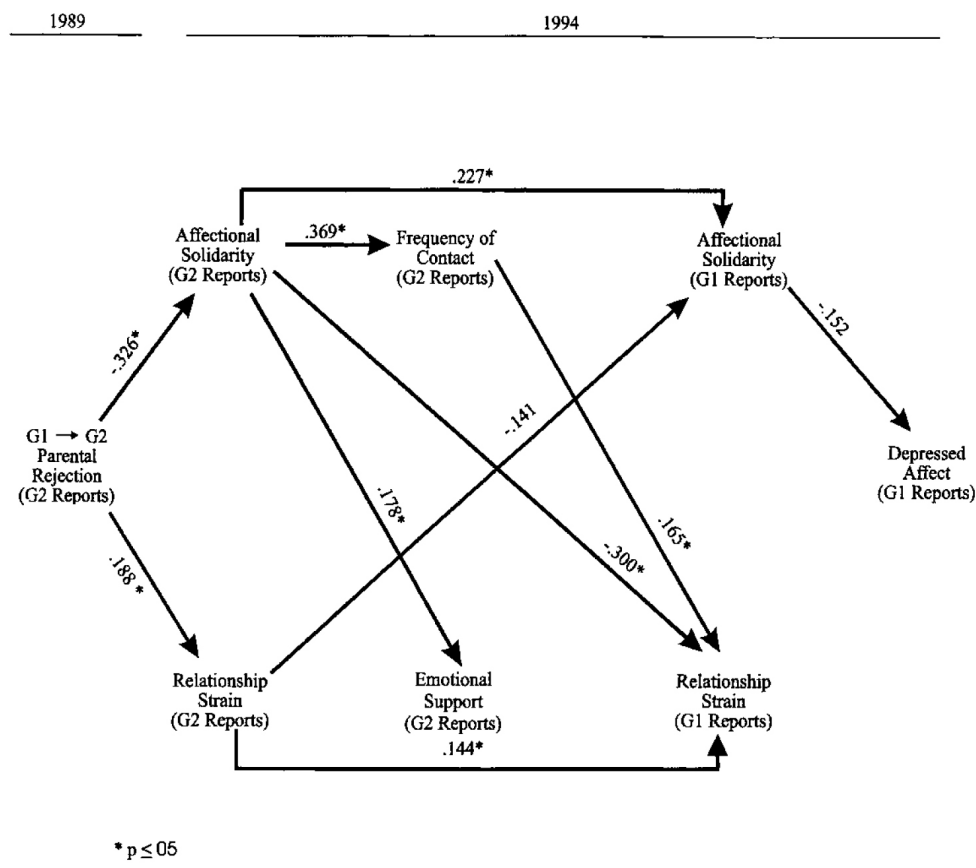

Figure 3. Model for male and female (G2) reports of fathers (G1), showing only statistically significant paths. $\mathrm{G} 1=$ Generation $1, \mathrm{G} 2=$ Generation 2. * $p \leq .05$.

to providing emotional support $(\beta=.18)$, frequency of contact $(\beta=.37)$, and fathers' reports of affectional solidarity $(\beta=.23)$. They were negatively associated with fathers' reports of relationship strain $(\beta=-.30)$. Adult children's reports of relationship strain were positively associated with fathers' reports on the same measure $(\beta=.14, p=.06)$ and negatively associated with fathers' reports of affectional solidarity $(\beta=$ $-.14, p=.06)$. Frequency of contact was positively related to fathers' reports of relationship strain $(\beta=.17, \mathrm{p}=.06)$. Aging fathers' perceptions of affectional solidarity with adult children were negatively associated with their reported depressive symptoms $(\beta=-.15)$. For aging fathers, a close relationship with adult children was associated with fewer depressive symptoms.

Among the control variables, proximity was associated with affectional solidarity between adult children and their fathers $(\beta=-.17)$ and frequency of contact $(\beta=-.48)$. Health of G1 fathers was associated with depressive symptoms $(\beta=.26)$. Fathers' health was positively related to 
adult children's reports of relationship strain $(\beta=.20)$ and children's reports of emotional support $(\beta=.17)$.

The full model explained $17 \%$ of the variance of fathers' reports of depressive symptoms, $16 \%$ of the variance of their reports of affectional solidarity with adult children, and $13 \%$ of the variance for relationship strain between generations.

\section{Discussion}

Two noteworthy findings emerged from these analyses. First, the effects of adult children's reported early parental rejection had consequences for their reported contemporary intergenerational relationship quality 5 years later. Second, intergenerational relationship quality was associated with depressive symptoms for aging parents of adult children. Although the adult children's recalled childhood experiences with their parents did not directly affect aging parents' reports of contemporary relationship quality, assessments of affectional solidarity and relationship strain by the two generations were significantly related in the same direction. Adult children's reports of affectional solidarity were related to frequency of contact with the older generation and the amount of emotional support provided to them. For the elderly mothers of adult children, relationship strain was positively associated with reports of depressive symptoms. For elderly fathers, affectional solidarity was negatively related to depressive symptoms. For aging women, the presence of relationship strain in at least one mother-adult child relationship was associated with depressed affect. For aging men, however, at least one caring relationship with an adult child was associated with fewer depressive symptoms.

Early family relationship histories set the stage for later life relationships in two ways. First, long-term patterns of relationship strain or low affectional solidarity between generations may contribute to later life depressed affect among elderly people. Second, negative interaction patterns that are continually reinforced across time may affect the ability of the family system to recognize the need for and effectively provide emotional support to elderly parents.

A limitation of these analyses is that the reports of relationship quality from both generations and parent reports of depressive symptoms were from the same year. An argument could easily be made that the effects are actually in the opposite direction from those hypothesized in the model. That is, depressed parents would be more likely to report poor relationships with their adult children, and adult children would report the same. During times of relationship difficulty, adult children would be 
more apt to recall their childhood relationships with their parents. However, the separation of recalled early family relationships and reports of contemporary relationships by 5 years indicates that the recollections of adult children about their childhoods had persistent effects across a significant period of time. Regardless of the direction of effects (i.e., whether intergenerational relationship quality contributes to depressed affect in elderly parents or whether depressive symptoms erode relationship quality), it is apparent that the ability to provide support is affected by relationship quality.

The lack of direct effects of adult children's reports of early family relationships on aging parents' reports is congruent with consistent findings that the elderly parent generation assesses intergenerational relationship quality more positively than its children (Bengtson \& Kuypers, 1971).

An important limitation of the study is the problem of generalizing from a rural, European American sample to the general population. Our findings must be replicated with more representative populations. Also, models matched by gender would improve confidence in the findings. Small cell sizes and a complex model prohibited such analyses with the present data.

In conclusion, these results provide some support for the hypothesis that family histories provide blueprints for later life family relationships. Early rejection by parents sets in motion a self-reinforcing dynamic that results in interactional continuity across the life course. These persistent interaction processes erode the ability of lineage systems to provide effective support for their aging members. Although limited to retrospective data, the present analysis provides a stronger test of the interactional continuity hypothesis by separating recalled and contemporary adult children's reports by 5 years and by including reporters from both generations in the model.

\section{Implications for Practitioners}

Anyone who works with families knows that family members develop unique patterns of communication and shared perceptions of family relationships. Our findings suggest that these communication patterns persist across time and affect families' abilities to meet the needs of aging parents in at least two ways: (a) a history of communication and relationship patterns may reduce the propensity of adult children to provide support; and (b) even given the willingness to provide support, poor communication patterns may reduce families' abilities to negotiate terms of support. Practitioners must be aware that family communication and relationship patterns have the force of history. They may be highly resistant to "easy fixes." In fact, attempts at "resolving" years of continually reinforced per- 
ceptions may not only be ineffective but may create discomfort by arousing old feelings of anger and hurt.

Intervention plans may need to focus on what is practical rather than what is "ideal." In highly dysfunctional families, support from adult children simply may not be forthcoming. In families with dysfunctional communication patterns, practitioners may need to help family members negotiate the specific terms of support through basic behavioral contracts. These contracts may be very similar to those negotiated by family therapists between adolescents and their parents. The same types of dynamic may still apply, although the family has aged.

Family communication and perceptions of relationships do not automatically change just because family members get older. Patterns of relationships in families tend to persist across time. The longer they persist, the more resistant to change they may become. In working with older families, the goal might be "working around" these patterns rather than "working through" them.

\section{References}

Bengtson, V., \& Kuypers, J. (1971). Generational differences and the developmental stake. Aging and Human Development, 2, 249-260.

Capaldi, D., \& Patterson, G. (1987). An approach to the problem of recruitment and retention rates for longitudinal research. Behavioral Assessment, 9, 169-177.

Caspi, A., Bem, D., \& Elder, G. (1989). Continuities and consequences of interactional styles across the life course. Journal of Personality, 57, 375-406.

Derogatis, L. (1983). SCL-90-R administration, scoring and procedures manual II (2nd ed.). Towson, MD: Clinical Psychometric Research.

Jackson, D. D. (1965a). Family rules: The marital quid pro quo. Archives of General Psychiatry, 12, 589-594.

Jackson, D. D. (1965b). The study of the family. Family Process, 4, 1-20.

Patterson, G. R. (1982). Coercive family processes. Eugene, OR: Castilia.

Rausch, H., Greif, A., \& Nugent, J. (1979). Communication in couples and families. In W. Burr, R. Hill, F. Nye, \& I. Reiss (Eds.), Contemporary research about the family (Vol. 1, pp. 468-489). New York: Free Press.

Whitbeck, L., Hoyt, D., \& Huck, S. (1994). Early family relationships, intergenerational solidarity, and support provided to parents by their adult children. Journal of Gerontology, 49, S85-S94.

Whitbeck, L., Simons, R., \& Conger, R. (1991). The effects of early family relationships on contemporary relationships and assistance patterns between adult children and their parents. Journal of Gerontology, 46, S330-S337. 
Les B. Whitbeck, Ph.D., earned his doctorate in sociology from Washington State University. He is currently a professor of sociology at Iowa State University, Institute for Social and Behavioral Research. His current research interests are highrisk children and adolescents and intergenerational relationships. Dr. Whitbeck's recent publications include "Depressive Symptoms and Co-Occurring Depressive Symptoms, Substance Abuse, and Conduct Problems Among Runaway and Homeless Adolescents" (Child Development) and "A Risk-Amplification Model of Victimization and Depressive Symptoms Among Runaway and Homeless Adolescents" (American Journal of Community Psychology).

Dan R. Hoyt, Ph.D., earned his doctorate in sociology from the University of Nebraska. He is currently a professor of sociology at Iowa State University, Institute for Social and Behavioral Research. His current research interests include the short-and long-term impacts of exposure to traumatic stressors, social support, and psychological distress among older, rural residents; and intergenerational relations. Dr. Hoyt's recent articles include "Personal Victimization in a High Risk Environment: Homeless and Runaway Adolescents" (Research in Crime and Delinquency) and "Psychological Distress and Help Seeking in Rural Places" (American Journal of Community Psychology).

Kimberly A. Tyler, Ph.D., received her doctorate in sociology from Iowa State University. She is an assistant professor of sociology at the University of Nebraska-Lincoln. Her research involves social support and depression among older adults, intergenerational relationships, and high-risk adolescents. Dr. Tyler's recent publications include "The Effects of an Acute Stressor on Depressive Symptoms Among Older Adults" (Research on Aging) and "The Effects of Early Sexual Abuse on Later Sexual Victimization Among Female Homeless and Runaway Adolescents" (Journal of Interpersonal Violence). 